\title{
Cloning and characterization of the human $\beta_{2}$-glycoprotein I $\left(\beta_{2}\right.$-GPI) gene promoter: roles of the atypical TATA box and hepatic nuclear factor- $1 \alpha$ in regulating $\beta_{2}-\mathrm{GPI}$ promoter activity
}

\author{
Hsueh-Hsiao WANG and An-Na CHIANG ${ }^{1}$ \\ Institute of Biochemistry, School of Life Science, National Yang-Ming University, Taipei 112, Taiwan, R.O.C.
}

\begin{abstract}
$\beta_{2}$-Glycoprotein I ( $\beta_{2}$-GPI) is a plasma glycoprotein primarily synthesized in the liver. The interindividual variability of $\beta_{2}$-GPI expression in subjects with various metabolic syndromes and disease states suggests that it may have clinical importance. However, the regulation of $\beta_{2}$-GPI gene expression has not been clarified. To gain more insight into the control of $\beta_{2}-G P I$ gene expression, we cloned the $4.1-\mathrm{kb} 5$-flanking region and characterized the proximal promoter of the $\beta_{2}-G P I$ gene in this study. $C i s$-acting elements required for $\beta_{2}-G P I$ promoter activity were identified with transient transfection assays in the hepatoma cell lines HepG2 and Huh7 and in non-hepatic HeLa cells. Serial deletion analyses of the $\beta_{2}$-GPI 5 '-flanking sequence revealed that the region from -197 to +7 had strong promoter activity in hepatoma cells but not in HeLa cells. Truncation and site-directed mutagenesis of putative cis-elements within this region showing
\end{abstract}

an atypical TATA box and a HNF-1 (hepatic nuclear factor-1) element were both essential for the $\beta_{2}-G P I$ promoter activity. Subsequent gel mobility shift assays confirmed the interaction of HNF-1 $\alpha$ with the HNF-1 site residing downstream of the TATA box. Co-transfection of $\beta_{2}$-GPI promoter-luciferase vector with HNF-1 $\alpha$ expression vector in Huh7 and HNF-1-deficient HeLa cells demonstrated the transactivation effect of HNF-1 $\alpha$ on $\beta_{2}$-GPI promoter activity. In addition, overexpression of HNF-1 $\alpha$ enhanced the endogenous $\beta_{2}$-GPI expression. These results suggest that the atypical TATA box and HNF-1 cis-element are critical for $\beta_{2}-G P I$ transcription and HNF- $1 \alpha$ may play an important role in cell-specific regulation of $\beta_{2}$-GPI gene expression.

Key words: gene regulation, $\beta_{2}$-glycoprotein I, hepatic nuclear factor- $1 \alpha(\mathrm{HNF}-1 \alpha)$, HepG2 cells, Huh7 cells.

\section{INTRODUCTION}

$\beta_{2}$-Glycoprotein I ( $\beta_{2}$-GPI), also known as apolipoprotein $\mathrm{H}$, is a monomeric glycoprotein of about $50 \mathrm{kDa}$ with 326 amino acids [1]. The sequence consists of five contiguous repeating units, each about 60 amino acid residues, which belong to the complement control protein superfamily [2,3]. In human plasma, $35 \%$ of $\beta_{2}$-GPI is associated with chylomicrons, very-low-density lipoprotein and high-density lipoprotein [4]. However, the majority is found in the lipoprotein-free fraction. It has been suggested that the physiological function of $\beta_{2}$-GPI is in lipid metabolism and intrinsic blood coagulation pathways $[5,6]$. In vitro, $\beta_{2}$-GPI inhibits both prothrombinase activity of activated platelets and ADP-dependent platelet aggregation [7-9]. $\beta_{2}$-GPI has been shown to be a cofactor for the recognition of anionic phospholipid antigen by autoantibodies appearing in anti-phospholipid syndrome (APS) [10-12] and such serum antibodies have been found to be associated with thrombotic events and recurrent miscarriage $[13,14]$. Moreover, $\beta_{2}$-GPI binds to oxidized lowdensity lipoprotein and inhibits its uptake by macrophages [15]. Our previous studies showed that $\beta_{2}$-GPI could inhibit $\mathrm{Cu}^{2+}$ induced oxidation of low-density lipoproteins and lipid accumulation in macrophages [16]. These findings indicate that $\beta_{2}$-GPI may have a protective role in the pathological events of oxidative stress and atherosclerosis.

$\beta_{2}$-GPI displays a genetically determined polymorphism $[17,18]$. Four alleles have been identified at a single locus on chromosome $17 \mathrm{q} 23$-qter. A wide range of variation in plasma $\beta_{2}$-GPI levels in different populations indicates that expression of
$\beta_{2}$-GPI may be under genetic regulation $[19,20]$. The main site of $\beta_{2}$-GPI synthesis is the liver and the level of $\beta_{2}$-GPI transcription in HepG2 cells is down-regulated by incubation with inflammatory mediators [21]. To date, little is known about the transcriptional regulation of $\beta_{2}-G P I$ expression. Thus, it is important to clarify the molecular basis of the $\beta_{2}$-GPI gene regulation through a characterization of its $c i s$-regulatory elements. We have cloned and sequenced a 4.1-kb genomic fragment corresponding to the $5^{\prime}$-flanking untranslated region of the human $\beta_{2}-G P I$ gene. We have further characterized the putative ciselements in the proximal promoter region and examined their importance in the transcriptional regulation. A molecular basis of controlling $\beta_{2}$-GPI gene expression has been preliminarily established in this study.

\section{EXPERIMENTAL}

\section{Cloning of the $5^{\prime}$-flanking region of the human $\beta_{2}$-GPI gene}

To clone the regulatory region of the human $\beta_{2}$-GPI gene, the GenomeWalker kit (Clontech, Palo Alto, CA, U.S.A.) was used according to the manufacturer's instructions. PCR reactions were performed with two sense primers supplied by the kit and two human $\beta_{2}$-GPI-specific antisense oligonucleotides 5'-CCGTCCTGCAATAGCAACATGGCAG-3' (position +63 to $+39 \mathrm{nt}$ ) and 5'-AGTCACACTGGCACTACCAAAGTGG-3' (position -9 to $-33 \mathrm{nt}$ ). The nucleotide position is referenced to the translation start site. PCR products were analysed on a $1 \%(\mathrm{w} / \mathrm{v})$ agarose gel. The target DNA fragments were cloned into pCRII

Abbreviations used: C/EBP $\beta$, CCAAT/enhancer binding protein $\beta$; EMSA, electrophoretic mobility shift assay; $\beta_{2}$-GPI, $\beta_{2}$-glycoprotein I; HNF, hepatic nuclear factor; NF-1, nuclear factor-1; SV40, simian virus 40

${ }^{1}$ To whom correspondence should be addressed (e-mail anchia@ym.edu.tw).

The nucleotide sequence data reported have been submitted to the GenBank ${ }^{\circledR}$ EMBL, DDBT and ESDB Nucleotide Sequence Databases under accession number AY376239. 
vector (Invitrogen, Carlsbad, CA, U.S.A.) and sequenced in both directions using the M13 forward and reverse primers by the ABI Prism automated DNA sequencer (Model 377). Based on the sequence, we were able to access the unknown $5^{\prime}$-genomic sequence of the human $\beta_{2}$-GPI promoter and were then able to design the following upstream primers. With multiple sets of $\beta_{2}-G P I$-specific oligonucleotides spanning $-358 /-384$ and $-536 /-562,-764 /-789$ and $-977 /-1002,-1414 /-1441$ and $-1448 /-1474,-1736 /-1762$ and $-2022 /-2048$, we strung the sequences together to create a $4.1-\mathrm{kb} 5^{\prime}$-flanking sequence of the human $\beta_{2}$-GPI gene.

\section{Primer extension}

Total RNAs were extracted from HepG2 and Huh7 cells as described in [22]. Three human $\beta_{2}$-GPI-specific antisense oligonucleotides, P1, 5'-GTCCTGCAATAGCAACATGG-3' (located in exon 1 , position +61 to $+42 \mathrm{nt}$ ), P2, 5'-TAACGGGACCACTGTGGAA-3' (located in exon 2, position +111 to $+93 \mathrm{nt}$ ) and P3，5'-ACAGGTCCGTCCTCGAATAG-3' (spanned exons 1 and 2 , position +69 to $+50 \mathrm{nt}$ ), were end-labelled with $\left[\gamma^{-32} \mathrm{P}\right]$ ATP using T4 polynucleotide kinase. The nucleotide position number is referenced to the translation start site. End-labelled probe (50000 c.p.m.) was annealed to $30 \mu \mathrm{g}$ of total RNA at $70{ }^{\circ} \mathrm{C}$ for $10 \mathrm{~min}$ and then chilled to ice-cold. The reverse transcription reactions were extended at $53^{\circ} \mathrm{C}$ for $1 \mathrm{~h}$ with 200 units of Superscript III reverse transcriptase (Invitrogen). Extended products were purified by phenol/chloroform extraction, precipitated with isopropanol, resuspended in formamide loading buffer, followed by heating at $90^{\circ} \mathrm{C}$ for $5 \mathrm{~min}$. The extended DNA fragments were resolved on a $6 \%$ denaturing polyacrylamide gel. To determine the 3 '-termini of the DNA fragments, a sequence ladder generated from the same oligonucleotide was loaded next to the extension products.

\section{Northern-blot analysis}

The multi-tissue blots were purchased from Life Technologies (Rockville, MD, U.S.A.) containing standardized levels of poly$(\mathrm{A})^{+}$(polyadenylated) RNA from various normal human tissues. The blots were hybridized with a ${ }^{32} \mathrm{P}$-labelled human $\beta_{2}-G P I$ cDNA fragment, encompassing +89 to $+606 \mathrm{nt}$ of the human $\beta_{2}$-GPI coding region, as described by the manufacturer. The blots were stripped and then rehybridized with a ${ }^{32} \mathrm{P}$-labelled $\beta$-actin cDNA probe as the positive control.

\section{Construction of reporter plasmids}

The promoterless reporter vector pGL2-basic (Promega, Madison, WI, U.S.A.) containing a firefly luciferase gene was used to clone the human $\beta_{2}$-GPI promoter fragment. Various deletions of the human $\beta_{2}$-GPI promoter were generated by PCR using highfidelity ExTAQ polymerase (Takara Shuzo, Kyoto, Japan) with human genomic DNA as template, and BglII-tagged sense and HindIII-tagged antisense primers. The amplified products were cleaved and subsequently cloned into BglII and HindIII sites of the pGL2-basic. To characterize the regulatory region of the human $\beta_{2}$-GPI gene, various 5'-deleted fragments were cloned into the SV40 (simian virus 40) promoter containing reporter vector pGL3-promoter (Promega) by the same PCR-based cloning techniques, with the exception that $M l u \mathrm{I}$-tagged sense and NheItagged antisense primers were used.

Site-directed mutations were generated by PCR using oligonucleotides listed in Table 1 and cloned into the pGL2-basic.
Table 1 Sequence of oligonucleotides used for mutagenesis of putative regulatory elements in the $\beta_{2}-G P I$ reporter constructs

The mutated nucleotides are underlined

\begin{tabular}{lll}
\hline Name & Sequence $\left(5^{\prime}-3^{\prime}\right)$ & Position \\
\hline TAm1L & ATACTTTATCTTCTATCTACAAAGATAA & $-109 /-82$ \\
TAm1R & ATAGAAGATAAAGTAT & $-94 /-109$ \\
TAm2L & CATGATACTTTATCTTCGCGCCGCAAAGATAAAAG & $-11 /-79$ \\
TAm2R & GAAGATAAAGTATCATG & $-97 /-113$ \\
CAm3L & GTCTCAGAGTTCCGACTCGATCATGATAC & $-134 /-106$ \\
CAm3R & GGAACTCTGAGAC & $-122 /-134$ \\
CAm4L & GATTTCATAACAGAGTTGTGCAGATGGAAAG & $-185 /-155$ \\
CAm4R & CTCTGTTATGAATC & $-171 /-185$ \\
HNF-1mL & AGAAAATGGTTCCTGTTGGAGC & $-72 /-51$ \\
HNF-1mR & AAGCGCTCCAACAGGAACCATT & $-47 /-68$ \\
HNF-3 $\beta$ NF-1mL & AAGCGCTCCTGTATCTGGCT & $-54 /-35$ \\
HNF-3 $\beta$ NF-1mR & ACAGAGCCAGATACAGGAGC & $-31 /-50$ \\
& & \\
\hline
\end{tabular}

For each mutant construct, the cloned fragment was divided into two individual PCR reactions. Two amplified fragments, covering 13-17 bp overlap, were obtained by using primers flanking the amplified regions with mutagenic oligonucleotides. The two PCR products were purified by QIAquick gel extraction column (Qiagen, Hilden, Germany) and mixed in the same molar concentration to perform a PCR with primers excluded. The extended product was further amplified with appropriate flanking primers and then cloned into $B g / \mathrm{II}$ and HindIII sites of pGL2-basic. All plasmid constructs were verified by sequencing with the dideoxy chain-termination method using $\left[\alpha-{ }^{35} \mathrm{~S}\right] \mathrm{dATP}$ and the T7 polymerase sequencing kit (Amersham Biosciences, Uppsala, Sweden). Oligonucleotides flanking the polylinker of plasmids were used as primers. Plasmid DNA used in transfection experiments was purified by the Concert nucleic acid purification system (Life Technologies).

\section{Cell culture, transfection and luciferase assays}

Human hepatoma cell lines (HepG2 and Huh7 cells) and human cervical carcinoma cell line (HeLa cells) were maintained in Dulbecco's modified Eagle's medium (DMEM) supplemented with $10 \%(\mathrm{v} / \mathrm{v})$ foetal bovine serum (FBS), 100 units $/ \mathrm{ml}$ penicillin, $100 \mathrm{mg} / \mathrm{ml}$ streptomycin, $0.3 \mathrm{mg} / \mathrm{ml} \mathrm{L}$-glutamine and $0.1 \mathrm{mM}$ non-essential amino acids at $37{ }^{\circ} \mathrm{C}$ under $5 \% \mathrm{CO}_{2}$ atmosphere. For transient transfection, cells were plated at a density of $1 \times 10^{5}$ cells/well in 24 -well plates the day before transfection and transfected using lipofectAMINE ${ }^{\mathrm{TM}} 2000$ reagent (Life Technologies) according to the manufacturer's instructions. For each transfection, $0.7 \mu \mathrm{g}$ of pGL2- or pGL3- $\beta_{2}-G P I$ reporter constructs were transfected along with $0.2 \mu \mathrm{g}$ of the internal control cytomegalovirus- $\beta$-galactosidase vector (pCMV- $\beta$-Gal). In co-transfection experiments, $0.7 \mu \mathrm{g}$ of $\beta_{2}$-GPI reporter constructs $(-197 /+7$ and mut $-197 /+7)$ and $0.1-0.3 \mu \mathrm{g}$ (as indicated) of $\mathrm{pRSV}$ or pRSV-HNF-1 $\alpha$ (where HNF stands for hepatic nuclear factor) vector driven by rous sarcoma virus longterminal repeat sequences were used. After $24 \mathrm{~h}$ of transfection, cells were harvested with $80 \mu \mathrm{l}$ lysis buffer $[70 \mathrm{mM}$ $\mathrm{K}_{2} \mathrm{HPO}_{4} / 55 \mathrm{mM}$ Tris/HCl, $\mathrm{pH} 7.8 / 2.1 \mathrm{mM} \mathrm{MgCl}_{2} / 0.7 \mathrm{mM}$ dithiothreitol/0.1\% (v/v) Nonidet P40/protease inhibitor cocktail from Calbiochem, San Diego, CA, U.S.A.]. Cell lysates were obtained by a repeated freezing and thawing procedure and the cellular debris was removed by centrifugation at $14000 \mathrm{~g}$ for $15 \mathrm{~min}$ at $4{ }^{\circ} \mathrm{C}$. The $\beta$-galactosidase assay was performed using $20 \mu \mathrm{l}$ of the cell lysate [22]. The luciferase assay was 
performed on $50 \mu 1$ of the cell lysate, $250 \mu 1$ of luciferase assay reagent (43 mM glycylglycine, $\mathrm{pH} 7.8 / 22 \mathrm{mM} \mathrm{MgSO}_{4} / 2.4 \mathrm{mM}$ EDTA/1 mM dithiothreitol/ $0.4 \mathrm{mg} / \mathrm{ml} \mathrm{BSA} / 7.4 \mathrm{mM}$ ATP), and $100 \mu \mathrm{l}$ of $0.5 \mathrm{mM}$ luciferin substrate (Promega). Luciferase activity was measured using a luminometer (EG\&G Berthold, Oak Ridge, TN, U.S.A.) and normalized with the $\beta$-galactosidase activity. The results are presented as means \pm S.D. of at least two independent constructs performed in triplicate.

\section{Electrophoretic mobility shift assay (EMSA)}

Extracts of nuclear proteins were prepared from Huh7 and HepG2 cells as described in [23]. The EMSA probes used are as follows (sense sequences are presented), $\beta_{2}-G P I$ wild-type HNF1 (5'-AGAAAATGGTTAATGTTTAAGCGCTT-3'), HNF3NF1(5'AAGCGCTTTCATATTTGGCTCTGT-3'), mHNF1 (5'-AGAAAATGGTTCCTGTTGGAGCGCTT-3') and consensus C/EBP (CCAAT/enhancer binding protein) (5'-TGCAGATTGCGCAATCTGCA-3'). The sequence underlined delineates the sitedirected mutation of the $\beta_{2}-$ GPI HNF-1 element. Sense and antisense oligonucleotides were heated at $90^{\circ} \mathrm{C}$ for $5 \mathrm{~min}$ and slowly cooled to room temperature $\left(25^{\circ} \mathrm{C}\right)$. The double-stranded oligonucleotides were labelled with $\left[\alpha-{ }^{32} \mathrm{P}\right] \mathrm{dCTP}$ by a fill-in reaction using the Klenow fragment of DNA polymerase I. The labelled probes were purified by spin column chromatography and probes of 50000 c.p.m. were used for each reaction in a final volume of $15 \mu \mathrm{l}$ containing $20 \mathrm{mM}$ Hepes (pH 7.5), $50 \mathrm{mM} \mathrm{NaCl}, 1.5 \mathrm{mM} \mathrm{MgCl} 2,5 \mathrm{mM}$ dithiothreitol, $100 \mu \mathrm{g} / \mathrm{ml}$ BSA, $1 \mu \mathrm{g}$ poly (dI/dC), $10 \%(\mathrm{v} / \mathrm{v})$ glycerol and various amounts of Huh7 and HepG2 nuclear extracts. Binding reactions were conducted in the absence or presence of specific or mutant competitors at room temperature for $30 \mathrm{~min}$. Competitors were generated by annealing the unlabelled sense and antisense oligonucleotides, and were added at 50-250-fold molar excess for each competition assay.

Supershift experiments were performed by adding $1 \mu \mathrm{g}$ of specific antibody after the binding reaction and incubating for an additional $15 \mathrm{~min}$ at room temperature. The following polyclonal antibodies (Santa Cruz Biotechnology, Santa Cruz, CA, U.S.A.) were used: anti-HNF-1 (sc-8986), anti-HNF-1 $\alpha$ (sc-6547), anti-HNF$1 \beta$ (sc-7411), anti-HNF-3 (sc-9187) and anti-NF-1 (sc-870). The completed reactions were resolved on a $4.5 \%$ non-denaturing polyacrylamide gel. The gel was dried and analysed using a PhosphorImager (Molecular Dynamics).

\section{Western-blot analysis}

Whole-cell extracts were prepared from Huh7 cells transfected with pRSV or $0.1-0.3 \mu \mathrm{g}$ of pRSV-HNF- $1 \alpha$ vector, as indicated. After $48 \mathrm{~h}$ of transfection, aliquots of whole cell lysates $(20 \mu \mathrm{g}$ of proteins) were electrophoresed on an SDS/10\%-polyacrylamide gel and electroblotted on to the nitrocellulose membrane (BioRad, Hercules, CA, U.S.A.). The blot was probed with rabbit anti-human $\beta_{2}$-GPI antisera produced in our laboratory [16] and visualized using horseradish peroxidase-coupled goat anti-rabbit secondary antibody (Zymed, South San Francisco, CA, U.S.A.) by ECL $^{\circledR}$ detection system (Amersham Biosciences). The blot was further stripped for probing with the $\alpha$-tubulin antibody (Zymed, San Francisco, CA, U.S.A.) as the internal control.

\section{RESULTS}

\section{Cloning of the human $\beta_{2}$-GPI gene promoter}

A 4.1-kb DNA fragment of the $\beta_{2}$-GPI $5^{\prime}$-flanking region was generated using the GenomeWalker kit with five sets of $\beta_{2}-G P I$
A

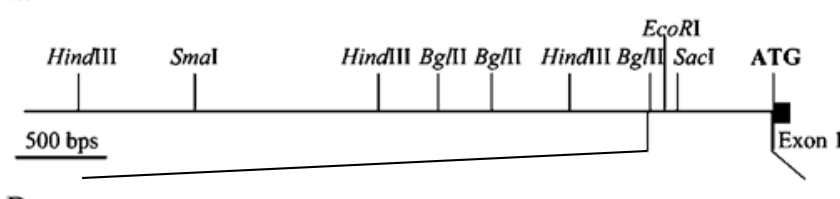

B

CAATTTTCAA ATTCCTGAAA CAGATCTAGA AACCTGTCTA GACAGATCCA AGACATACTA -620 AGAATGGATG AGGAGGACTT TGTATTGATC TGACGTAAGA GAAGATAGAG AATTCAAGGA -560 TAGCTCTAAG GTOCTAACTG GAGCTATAGG $\frac{\text { AGCTTGCAAG AGAGGATGTT GAGCTCAGTT }}{\text { C/EBPB }}$ TGTAGCGAAT TAAAGTTGTA AGTGCCTCCT GGAAGACATT CTTTGTAATT ATACATCTGA -440 AAACTGGAAC ATCATTTTAG AGAGGTGGAG ACTGAGAACA GAGAGTAGGT GTTTGTCCAA -380 $\frac{\text { AGTTTATATG CCAAGGCTGT GAGTGAAACA GGAGCTTCGA TCTTTTGGTG TTCCATCTAC }-320}{\text { NF-1 }}$ NF-1
AACATACACA AAACAAAAGA TGG

TTCTGTCAAA ACCAATAATG AACIGTTTTG TGCCATTAAC AAAAACGTTA TGAAGACAGA -200 HNF-3B

AACCATCTCC CAAAGATTTC ATAACAGAGC CACATAGATG GAAAGTAAAT GATTAAAGAA -140

TGTGGGTCTC AGAGTTCCAT TCAAATCATG ATACTTTATC TTCTATTTAC AAAGATAAAA -80

GTACACCAGA AAATGGTTAA TGTTTAAGCG CTTTCATATT TGCCTCTGTC TTTTTAGCAG -20

ACGAAAACCA CTTTGGTAGT GCCAGTGTGA CTCATCCACA ATG +24

Figure 1 Structural organization and nucleotide sequence of the $5^{\prime}$-flanking region of the human $\beta_{2}-G P I$ gene

(A) The horizontal line represents the structure of human $\beta_{2}$-GPI5'-flanking region derived from the five GenomeWalker clones as described in the Experimental section. Restriction enzymes used in mapping and subcloning are shown as vertical lines. The translation start codon ATG is shown in bold-type. (B) Nucleotide sequence of the genomic region surrounding the putative promoter region. The sequence is indicated in base pairs relative to the first nucleotide of the transcription start site for $\beta_{2}$-GPI, designated as +1 .

specific primers. To amplify the assembled fragments, we conducted a PCR with human chromosome template, sense and antisense primers corresponding to positions - 3993/-3970 and $+13 /-12$, respectively. The PCR product was cloned into pCRII vector and verified by bidirectional nucleotide sequencing and restriction digestion (Figure 1A). A BLAST search of known sequences in the nucleotide sequence databases was used to identify DNA similarity. No typical promoter sequence was present. A sequence derived from the bacteria artificial chromosome clone of human chromosome 17 was aligned $\left(\mathrm{GenBank}^{\circledR}\right.$ accession number AC006120). The region -636 to +24 corresponded to a structural gene of the human $\beta_{2}$-GPI [24]. The potential transcription factor binding sites identified by the MatInspector program, using the TRANSFAC 4.0 matrices [25], with a core similarity of 1.00 and a matrix similarity of over 0.85 , are shown in Figure 1(B).

\section{Identification of the transcription start site of the human $\beta_{2}$-GPI gene}

Several human $\beta_{2}$-GPI cDNA sequences submitted to the nucleotide databases possessed various 5 '-ends [24,26-28]. To map precisely the $\beta_{2}-G P I$ transcription start site, a chimaeric construct containing a conjunctive 5 '-flanking sequence as well as exons 1 and 2 of the $\beta_{2}-G P I$ gene was used as the template for the sequence ladder in primer extension analysis. Three ${ }^{32} \mathrm{P}$-labelled primers, complementary to regions $+61 /+42$ (Figure $2 \mathrm{~A}),+111 /+93$ (Figure 2B) and $+69 /+50$ (Figure 2C) from the ATG codon of $\beta_{2}-G P I$ cDNA, were extended using total RNA from HepG2 and Huh7 cells as template. The human hepatoma cell lines HepG2 and Huh7 cells express $\beta_{2}-G P I$ at high levels when analysed by 


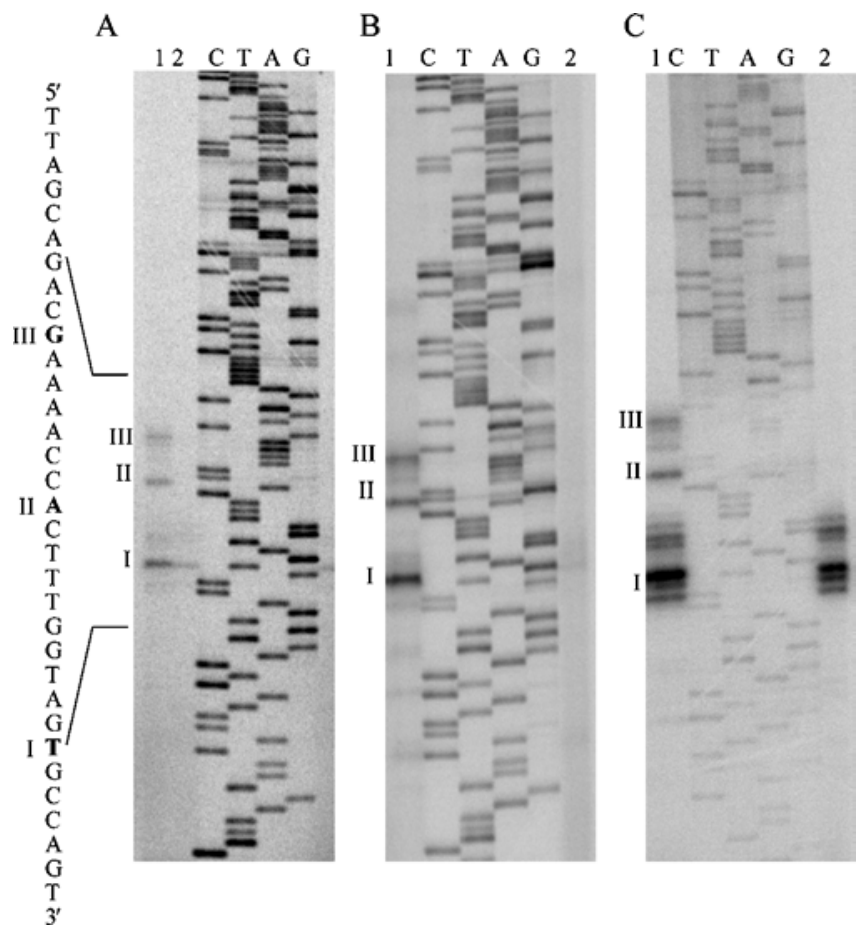

Figure 2 Determination of the transcription start site of the human $\beta_{2}$-GPI gene

Primer extension analysis was conducted with three oligonucleotides, P1 (A), P2 (B) and P3 (C), annealing to total RNA from HepG2 (lane 1) or Huh7 (lane 2) cells. The adjacent lanes (C, $\mathrm{T}, \mathrm{A}$ and $\mathrm{G}$ ) represent the DNA sequence reactions generated by the same oligonucleotide with a genomic fragment including exons 1 and 2 as the template. The transcription start sites are indicated by I, II and III in the order of mobility. The corresponding nucleotide sequence is indicated on the left.

reverse transcription-PCR and Western blot (results not shown). The same results were obtained with these three primers (Figure 2). One predominant transcription start site (site I) was detected at a thymidine residue, $21 \mathrm{bp}$ upstream from the translation start site of RNAs both in HepG2 and Huh7 cells. However, two additional extension products were obtained with RNAs of HepG2 cells, one (site II, residue A) at $31 \mathrm{bp}$ and the other (site III, residue G) at 38 bp upstream from the ATG codon. The transcription start site named site I will be hereafter used as the reference point and designated +1 . Neither a conserved TATA nor CAAT box was identified within $100 \mathrm{bp}$ of the transcription start site.

\section{Localization and identification of the promoter sequence required for basal $\beta_{2}-$ GPI promoter activity}

Northern-blot analysis showed that human $\beta_{2}-G P I$ gene was predominantly expressed in the liver (Figure 3). The neural network promoter prediction (NNPP) program [29] and Promoter 2.0 prediction server [30] predicted a promoter of $\beta_{2}$-GPI gene residing around -1904 . To map the promoter region required for initiating the $\beta_{2}-G P I$ gene transcription, we conducted functional analyses of the $\beta_{2}$-GPI 5'-flanking sequence. Various luciferase reporter constructs were transiently transfected into Huh7 and HepG 2 cells. The $-2057 /-1096$ reporter construct containing the predicted promoter region displayed no promoter activity. However, the construct containing -616 to +7 fragment generated a 137- and 51-fold induction over the promoterless construct (pGL2-basic) in Huh7 and HepG2 cells, respectively (Figure $4 \mathrm{~A}$ ). The abundance of binding sites for transcription factors

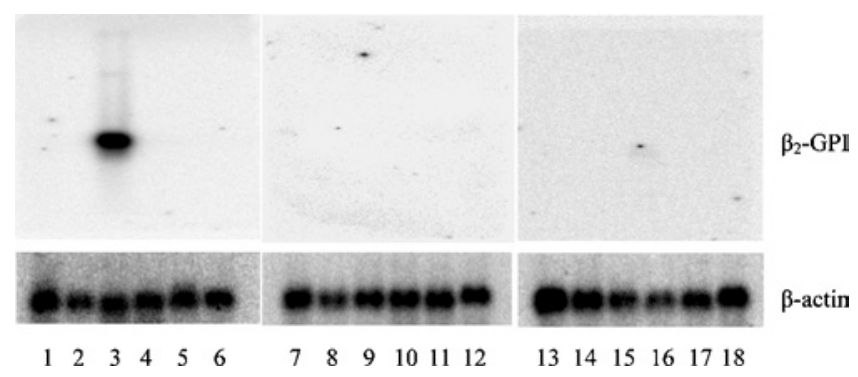

Figure 3 Northern-blot analysis of the human $\beta_{2}$-GPI gene expression

Blots containing standardized levels of poly $(\mathrm{A})^{+}$mRNA from selected human tissues were hybridized with the ${ }^{32}$ P-labelled human $\beta_{2}$-GPI CDNA probe. Lane 1, heart; lanes 2 and 7 , brain; lane 3, liver; lane 4, pancreas; lane 5, skeletal muscle; lanes 6, 12 and 18, lung; lane 8, uterus; lane 9, placenta; lane 10, kidney; lane 11, spleen; lane 13, stomach; lane 14, jejunum; lane 15, ileum; lane 16, colon; lane 17, rectum. These filters were stripped according to the manufacturer's instructions and then rehybridized with a ${ }^{32} P$-labelled $\beta$-actin cDNA probe.

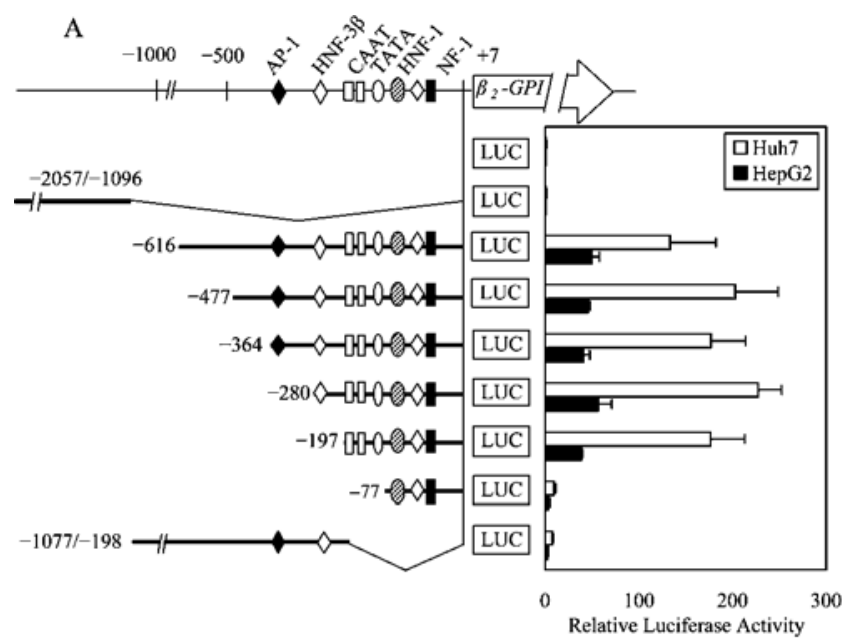

B

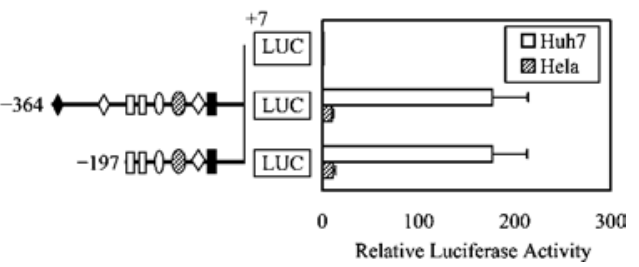

Figure 4 Deletion analysis of the regulatory region of the human $\beta_{2}-G P I$ gene

The scheme represents the luciferase (LUC) reporter gene driven by the human $\beta_{2}$-GPI promoter and the relative luciferase activities. The $5^{\prime}$-ends of these constructs were numbered in base pairs relative to the $\beta_{2}-G P I$ transcription start site, and the putative cis-elements are indicated at the top. (A) The reporter constructs containing sequentially deleted $5^{\prime}$-flanking fragments were cloned and transiently transfected into Huh7 and HepG2 cells as described in the Experimental section. (B) For examining cell-specific transcriptional regulation, pGL2B $-364 /+7$ and pGL2B $-197 /+7$ constructs were transfected into Huh7 and HeLa cells. A pCMV- $\beta$ galactosidase vector encoding $\beta$-galactosidase was co-transfected as an internal control. The luciferase activity was normalized against $\beta$-galactosidase activity and indicated as the relative value of the activity of promoterless pGL2-basic vector (set as 1). Results are expressed as the means + S.D. for at least two independent experiments performed in triplicate.

in the proximal $0.7-\mathrm{kb} \beta_{2}-G P I$ promoter suggests that this region may confer transcriptional activity in hepatoma cells (Figure 1A). To define further which sites in the $\beta_{2}-G P I$ promoter region were essential for the transcription, we constructed a series 
A

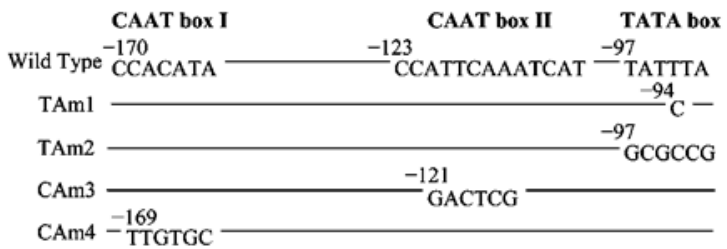

B

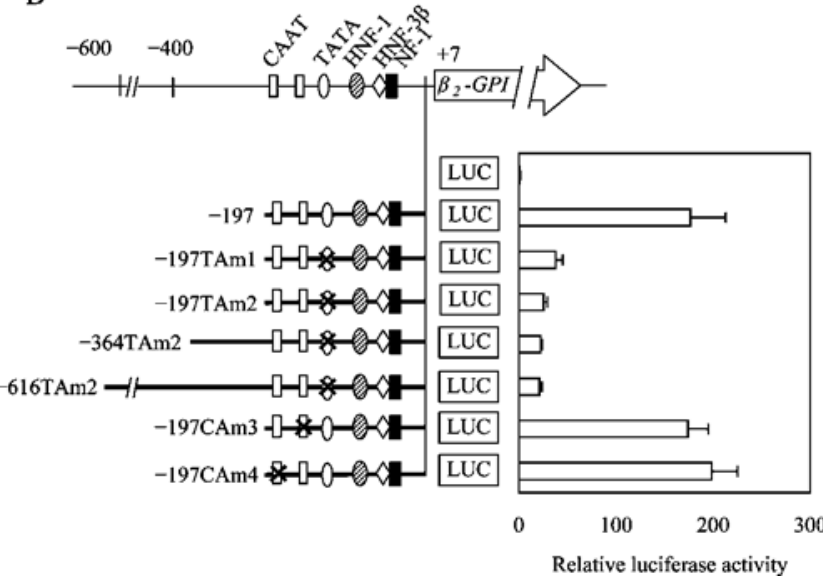

Figure 5 Identification of one TATA box and two CAAT boxes in the $\beta_{2}$-GPI promoter required for the basal promoter activity of the human $\beta_{2}$-GPI gene

(A) DNA fragments of wild-type and mutants containing one or six mutated bases in TATA box (TAm1 and TAm2) or CAAT boxes (CAm3 and CAm4) were designed for mutational analysis. Only the mutated bases are indicated and their nucleotide positions are numbered corresponding to base pairs upstream of the transcription start site. (B) Site-directed mutants, schematically shown on the left side, were connected with pGL2-basic vector and transiently transfected into Huh7 cells. A pCMV- $\beta$-galactosidase vector encoding $\beta$-galactosidase was co-transfected as an internal control. The luciferase activity was normalized against the $\beta$-galactosidase activity and indicated as the relative value of the activity of promoterless pGL2-basic vector (set as 1). Results are expressed as means \pm S.D. for at least two independent experiments performed in triplicate.

of deletion derivatives in the $5^{\prime}$-flanking region. No significant change in promoter activity was observed in constructs extending beyond position - 198 (Figure 4A). However, luciferase activity was almost completely abolished (95\% decrease in Huh7 cells and $91 \%$ decrease in HepG 2 cells) by a further deletion extending to position -77 . The 3 '-end deletion construct, with removal of 204 bp from position -197 to +7 exhibited the same reduction. Similar results were obtained in both Huh7 and HepG2 cells. However, when the $-364 /+7$ and $-197 /+7$ reporter constructs were transfected into HeLa cells to determine the cell-type specificity of the $\beta_{2}$-GPI promoter, the two constructs displaying high luciferase activities in hepatoma cells had negligible effect in HeLa cells (Figure 4B). These results indicate that the sequence required for $\beta_{2}-G P I$ promoter activity in Huh7 and HepG 2 cells is located within $121 \mathrm{bp}$ from -197 to -78 . The proximal 204 bp region $(-197$ to +7$)$ of the $\beta_{2}-G P I$ promoter is sufficient to confer a high level of transcriptional activity in hepatoma cells.

We found an atypical TATA box (TATTTA) located between -97 and -92 , and two atypical CAAT boxes in the region between -197 and -78 , CAAT box I (CACAT) at position - 170 and CAAT box II (CCATT) at position - 123 (Figure 5A). Site-directed mutagenesis was performed to verify whether the atypical TATA box and CAAT boxes were functional. The positions and nature of the base substitutions are shown in Figure 5(A). The mutations in the CAAT boxes did not affect the promoter activity when compared with the wild-type $-197 /+7$

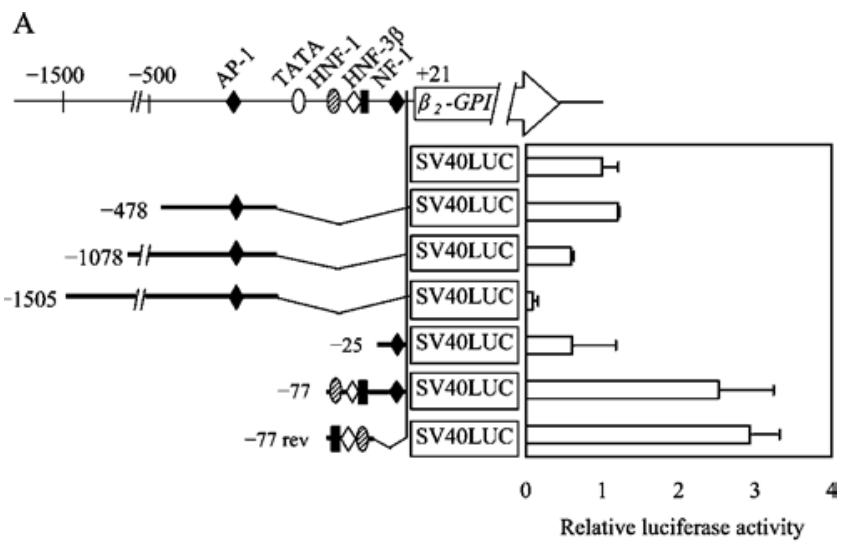

B $\begin{array}{lllll}-71 & \text { HNF-1 } & \text { HNF-3 } & \text { NF-1 } & -30\end{array}$ Wild Type GAAAATGGTTAATGTIIAAGCGCTITCATATITGGCTCTGTC $\begin{aligned} \text { mHNF-1 } & -61 \\ \text { mHNF-3 } 3 \text { NNF-1 } & \end{aligned}$

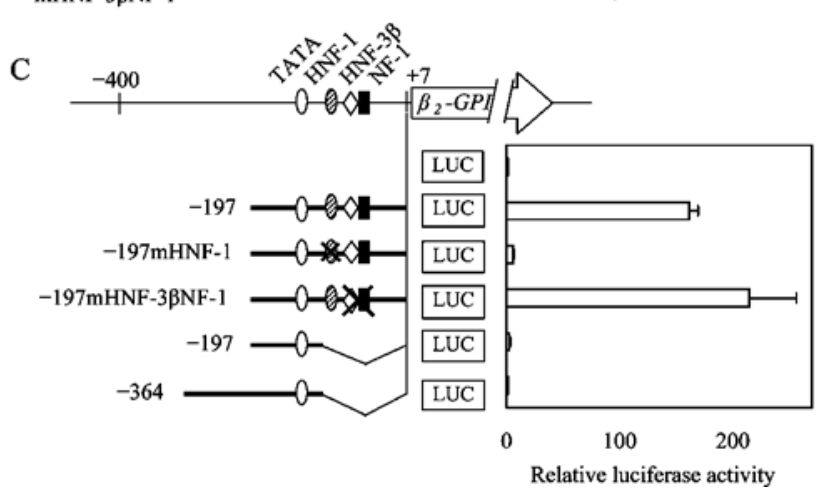

Figure 6 Identification of the $\beta_{2}$-GPI promoter region containing the cisregulatory element that confers the enhancer activity

(A) DNA fragments exclusive of the atypical TATA box region of the human $\beta_{2}$-GPI promoter, schematically shown on the left side, were connected with the minimal SV40 promoter and the firefly luciferase gene (pGL3-promoter vector). These constructs were transiently transfected into Huh7 cells with $\mathrm{pCMV}-\beta$-galactosidase vector as the internal control. The luciferase activity was normalized against the $\beta$-galactosidase activity and indicated as the relative value of the activity of pGL3-promoter vector (set as 1). Results are expressed as means \pm S.D. for at least two independent experiments performed in triplicate. (B) DNA fragments of wild-type and mutants containing the putative HNF-1 (mHNF-1), HNF-3 $\beta$ and NF-1 (mHNF-3 $\beta$ NF-1) cis-elements were designed for mutational analysis. Only the mutated bases are indicated and the nucleotide positions are numbered corresponding to the transcription start site (as +1$)$. (C) Site-directed mutants, shown on the left side, were connected with pGL2-basic vector and transfected into Huh7 cells with pCMV- $\beta$-galactosidase vector as the internal control. The luciferase activity was normalized against the $\beta$-galactosidase activity and indicated as the relative value of the activity of promoterless pGL2-basic vector (set as 1).

reporter construct (Figure 5B). However, a single-base mutation introduced into the TATTTA box $(-197$ TAm1) led to a $79 \%$ decrease of promoter activity, suggesting a pivotal role of this atypical TATA element for promoter induction (Figure 5B).

\section{Analyses of enhancer activity and characterization of the enhancer region}

To define whether the sequence surrounding the atypical TATA element contains other regulatory elements, we subcloned a group of promoterless fragments to $5^{\prime}$ of a SV40 promoter plasmid (pGL3-promoter) and transfected them into Huh7 cells. The results of the transfection assay are shown in Figure 6(A). No 
enhancer activity was observed in the sequence upstream of the TATA element. Extension from - 1078 to -1505 led to a $91 \%$ decrease in promoter activity, suggesting the presence of a suppressor in this region. However, the region downstream of the TATA element $(-77 /+21)$ increased the promoter activity over 2.6 -fold (Figure 6A). Deletion of the region -77 to -25 reduced luciferase activity to the level of SV40 promoter background. When the $3^{\prime}$ sequence was deleted from +21 to -25 and subcloned in an antisense direction, the activity remained the same as the $-77 /+21$ construct. These results indicate that the region -77 to -25 may contribute to $\beta_{2}$-GPI promoter activity as an enhancer. Since this region contains three putative cis-elements of HNF-1, HNF-3 $\beta$ and NF-1 (nuclear factor-1), site-directed mutagenesis was conducted to investigate the possible role of these three elements in $\beta_{2}-$ GPI promoter activity (Figure 6B). Mutation of the palindromic structure of the HNF-1 element decreased the reporter activity by $96 \%$ compared with that of the $-197 /+7$ construct, whereas the mutation in the HNF-3 $\beta$ and NF-1 elements did not affect the reporter activity (Figure 6C). Reporter constructs (region $-197 /-77$ or $-364 /-77$ ) containing the atypical TATA element but not the three putative ciselements were unable to perform transcription of the luciferase reporter (Figure 6C). This indicates that the TATTTA sequence is unable to initiate transcription by itself. However, when the HNF1 element is included in the reporter construct, promoter activity was achieved (Figures 4A and 6C). These findings show that the sequence from -77 to -25 contains the enhancer element, and that both TATTTA sequence and the HNF-1 element are necessary for the transcription of the reporter gene.

\section{HNF-1 $\alpha$ binds to the proximal $\beta_{2}$ - GPI promoter}

Results from transfection experiments show that the atypical TATA box and HNF-1 element of the $\beta_{2}-G P I$ promoter drive luciferase expression in hepatoma cells. To identify nuclear proteins interacting with the putative HNF-1 element, EMSAs were performed using two probes spanning from -72 to -47 and from -54 to -31 respectively (Figure $7 \mathrm{~A}$ ). The $\beta_{2}-G P I$ wildtype HNF1 fragment $(-72 /-47)$ formed two $(\mathrm{C} 1$ and $\mathrm{C} 2)$ and one (C1) specific DNA-protein complexes with Huh7 and HepG2 nuclear extracts respectively (Figure 7A, lanes 2-5). Both complexes were competed by unlabelled HNF1 oligonucleotide (Figure 7A, lanes 6-8). However, the mutant (mHNF1) oligonucleotide did not compete for nuclear protein interaction (Figure 7A, lanes 9-11). To determine whether the proximal sequence from -54 to -31 , comprising a HNF- $3 \beta$ site and a NF-1 site, could be bound by nuclear factors, additional EMSA was conducted. The HNF3NF1 probe bound a complex in nuclear extracts of HepG2 and Huh7 cells (Figure 7A, lanes 13 and 14) but this non-specific band was competed by 25 -fold molar excess of unlabelled C/EBP competitor in both cell lines (Figure 7A, lanes 15 and 16). To identify further the protein factors that form complexes with the transcriptional elements, supershift EMSA was conducted by incubating nuclear extracts from Huh7 cells with the radiolabelled HNF1 probe in the presence of anti-HNF-1, anti-HNF-3 or anti-NF-1 antibodies. Both C1 and C2 complexes were supershifted when the anti-HNF-1 antibody was added (Figure 7B, lane 2). In contrast, no supershift complex was detected with antibodies against HNF-3 or NF-1 (Figure 7B, lanes 3 and 4). The supershift complex was displaced by the unlabelled wild-type competitor (HNF1), whereas no competition was found with the mutant mHNF1 competitor. Since HNF-1 consists of two isoforms (HNF-1 $\alpha$ and HNF-1 $\beta$ ) that bind the transcriptional element as either homo- or heterodimers [31,32], additional EMSA in the presence of antibodies specific to
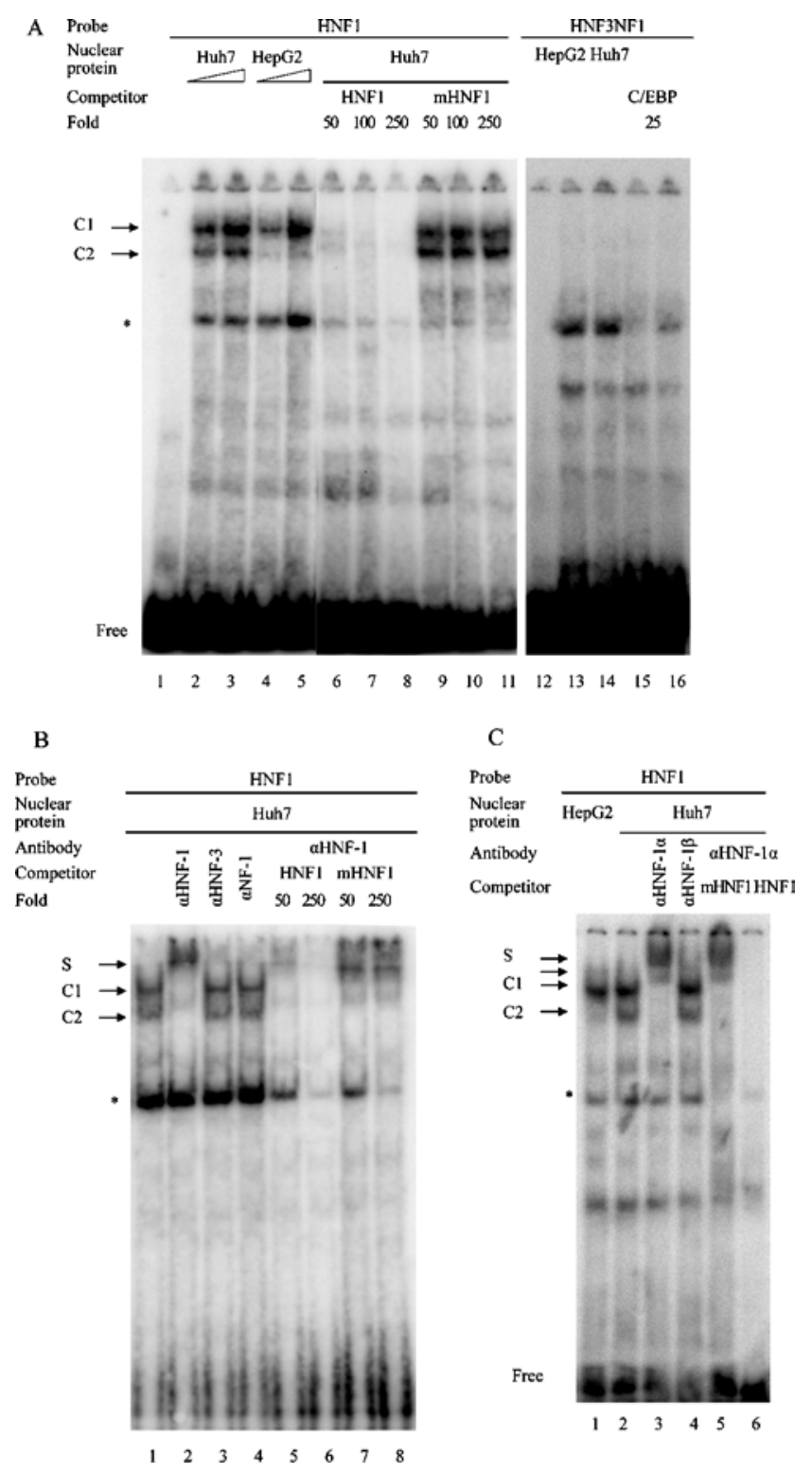

Figure 7 Competition EMSA performed to analyse the binding specificity of the HNF-1 site of the $\beta_{2}$-GPI promoter

(A) The ${ }^{32}$ P-labelled DNA fragments from -72 to -47 (HNF1) and -54 to -31 (HNF3NF1) derived from the human $\beta_{2}$-GPI promoter region were used as probes in the absence or presence of nuclear extract from Huh7 or HepG2 cells. Competitors used are indicated at the top of the gel. Lane 1, HNF1 probe alone; lanes 2-5, HNF1 probe plus increasing amounts of nuclear extract from Huh7 or HepG2 cells; lanes 6-8, in presence of unlabelled HNF1 probe; lanes 9-11, in the presence of mutated HNF1 oligonucleotide (mHNF1); lane 12, HNF3NF1 probe alone; lanes 13-16, HNF3NF1 probe with nuclear extract from HepG2 or Huh7 cells in the absence or presence of non-related competitor (consensus C/EBP). (B) Identification of the protein interacting with the HNF-1 cis-element. Lane 1, HNF1 probe plus nuclear extract from Huh7 cell; lanes 2-4, DNA-protein complexes (C1 and C2) were incubated with specific antibodies against HNF-1, HNF-3 or NF-1 respectively; lanes 5-8, anti-HNF-1 antibodies in the presence of unlabelled HNF1 probe or mutated HNF1 oligonucleotide (mHNF1). (C) Interaction of HNF-1 $\alpha$ with the HNF-1-binding site of the human $\beta_{2}$-GPI promoter. Lanes 1 and 2, HNF1 probe with nuclear extract from HepG2 or Huh7 cells; lanes 3 and 4, in the presence of specific anti-HNF- $1 \alpha$ or $1 \beta$ antibodies; lanes 5 and 6 , supershift complexes were incubated with mutated HNF1 oligonucleotide (mHNF1) or unlabelled HNF1 probe. The asterisk denotes non-specific interaction bands. Specific DNA-protein complexes are indicated by ' $C$ ', and the supershift bands are indicated by 'S'. 'Free' refers to the free probe.

HNF- $1 \alpha$ and $-1 \beta$ was also carried out. Only anti-HNF- $1 \alpha$ antibody affected the migration of the $\mathrm{C} 1$ and $\mathrm{C} 2$ complexes (Figure $7 \mathrm{C}$, lane 3 ). The supershift complex was displaced by the 

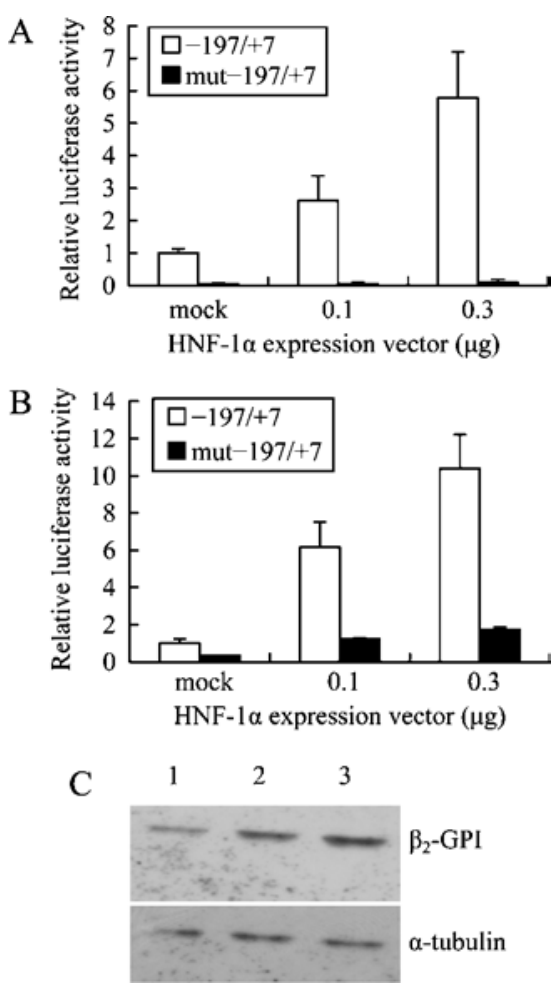

Figure 8 Transactivation of human $\beta_{2}$-GPI expression by HNF-1 $\alpha$

The pGL2B $-197 /+7$ and pGL2Bmut $-197 /+7$ constructs were co-transfected into Huh7 (A) and HeLa (B) cells with 0.1 or $0.3 \mu \mathrm{g}$ of HNF-1 $\alpha$ expression vector (pRSV- HNF-1 $\alpha$ ) or a control vector (pRSV). Luciferase activities were indicated as activities relative to that of the control vector. Results were represented as means \pm S.D. of three independent experiments. (C) Huh7 cells were transiently transfected with 0.1 or $0.3 \mu \mathrm{g}$ of HNF-1 $\alpha$ expression vector (lanes 2 and 3) or the $0.3 \mu \mathrm{g}$ pRSV control vector (lane 1). The expression of endogenous $\beta_{2}-\mathrm{GPI}$ is shown by a representative gel of Western-blot analysis with the internal control probed by the anti- $\alpha$-tubulin antibody.

unlabelled excess HNF1 (Figure 7C, lane 6) but not by mHNF1 (Figure 7C, lane 5). However, nuclear factors binding to HNF1 fragment were not affected by anti-HNF-1 $\beta$ antibody (Figure 7C, lane 4). The supershift assay indicates that homodimeric HNF- $1 \alpha$ bound the proximal enhancer through the palindromic sequence at the region from -65 to -51 .

\section{Transactivation of the $\beta_{2}$-GPI promoter with HNF-1 $\alpha$}

The results in Figures 6 and 7 demonstrated that HNF- $1 \alpha$ bound to region $-65 /-51$ within the $\beta_{2}-G P I$ proximal promoter which conferred a high-level of transcriptional activity. These results suggest that HNF- $1 \alpha$ may regulate the expression of $\beta_{2}-G P I$ gene in hepatoma cells. To test this hypothesis, we conducted cotransfection experiments in Huh7 cells and a non-hepatic cell line (HeLa cells) using the $-197 /+7$ construct that contains the atypical TATA box and the HNF-1 element, along with pRSVHNF- $1 \alpha$ expression vector. As shown in Figures 8(A) and 8(B), the $-197 /+7$ construct was activated by HNF-1 $\alpha$ in a dosedependent manner. Co-transfection of Huh7 and HeLa cells with the wild-type $-197 /+7$ construct along with $0.3 \mu \mathrm{g} \mathrm{HNF}-1 \alpha$ expression vector induced luciferase activity by 5- and 11-fold, respectively. This induction was shown to be absolutely dependent on the presence of the wild-type HNF-1 element since the mutated $-197 /+7$ construct displayed a drastic decrease in transactivation. We then examined the ability of HNF-1 $\alpha$ to regulate endogenous $\beta_{2}$-GPI expression. Western-blot analysis showed that endogenous levels of $\beta_{2}$-GPI in Huh7 cells were increased after transfection with the HNF-1 $\alpha$ expression vector, and the increase was dose-dependent (Figure 8C). Taken together, these results indicate that the HNF-1-binding site is functional and that HNF- $1 \alpha$ is capable of activating human $\beta_{2}$-GPI gene transcription.

\section{DISCUSSION}

Although the role of the human $\beta_{2}-G P I$ gene product has received increasing attention in recent years, surprisingly little is known about the transcriptional regulation of this gene. In this study, we have cloned and characterized the $\beta_{2}-G P I$ promoter immediately upstream of the transcriptional start site, and have identified transcriptional factors involved in the regulation of $\beta_{2}-G P I$ expression.

The transcription initiation sites of the human $\beta_{2}$-GPI gene were previously considered to be located at 21 and $31 \mathrm{bp}$ upstream of the translational start site in human genomic DNA [24]. In contrast, our results show that the major transcription start sites are located at 21,31 and $38 \mathrm{bp}$ upstream of the $\beta_{2}$-GPI gene in HepG 2 cells and at $21 \mathrm{bp}$ in Huh7 cells. The primer extension analyses, which were performed under high stringency and with different probes, have identified the same 5 '-terminal nucleotides suggesting the validity of our results. The high degree of identity at the $-21 \mathrm{bp}$ site suggests that this may be the major transcription start site although the -31 bp site agrees completely with the consensus for an initiator element, PyPyA ${ }_{+1} \mathrm{~N}(\mathrm{~T} / \mathrm{A}) \mathrm{PyPy}$ known to sustain transcription initiation [33]. The -21 bp site, the most distinct band in the primer extension study, was assigned mRNA position +1 in our latter experiments.

In this study, Northern-blot analysis revealed that liver is the major site for $\beta_{2}$-GPI expression, but a trace amount of $\beta_{2}-G P I$ mRNA was detected in the intestine and placenta by reverse transcription-PCR (results not shown). Transfection studies showed that the 5 '-flanking sequence of the $\beta_{2}$-GPI gene contained a functional promoter that was able to drive luciferase expression efficiently in hepatoma cells but not in HeLa cells. This result suggests that cell-type-specific transcription factors may be involved in mediating differential expression of the human $\beta_{2}-G P I$ gene. Interestingly, the location of this functional promoter disagrees with the predicted promoter region derived from both the NNPP program and Promoter 2.0 prediction server. Such a distinction indicates that $\beta_{2}-G P I$ promoter may have novel ciselements or unique arrangement of regulatory elements. Our results demonstrate that the first $100 \mathrm{bp}$ upstream of the transcription start site contains all of the necessary elements to confer hepatic-specific expression of the $\beta_{2}$-GPI gene. Results from the 5 '-deletion and transient transfection assays suggest that the atypical TATA box between nucleotides -97 to -92 and a downstream HNF-1 cis-element are essential for the promoter activity of the $\beta_{2}$-GPI gene in hepatoma cells. Gel retardation and competition experiments strongly suggest that proximal cis-acting elements bind the transcription factor HNF-1 $\alpha$ in the nuclear extract of hepatic cells.

A number of reports showed that TATA box and initiator element may interact with transcription factors to form a stable transcription initiation complex and to accomplish efficient and accurate transcription $[34,35]$. Our observations indicate that the $\beta_{2}$-GPI promoter possesses an atypical TATA box and several adjacent $c i s$-acting elements, and raises the obvious question as to what possible transcription machinery might the $\beta_{2}-G P I$ gene expression require? We have demonstrated that mutation of the HNF-1 site in the $\beta_{2}$-GPI promoter greatly impaired its promoter 
activity. The HNF-1 site is adjacent to the transcription initiation site, suggesting that the HNF-1 site may play a crucial role in directing transcription initiation. The transcription factor HNF-1 encompassing two isoforms, HNF- $1 \alpha$ and HNF-1 $\beta$ [36], was originally isolated from liver and differentiated hepatoma cells [37]. HNF-1 has subsequently been found to be involved in the transcriptional regulation of many hepatic genes, such as albumin, $\alpha$-fetoprotein and phenylalanine hydroxylase [37-39].

In the present study, co-transfection of the $\beta_{2}$-GPI promoterdriven luciferase reporter with the HNF- $1 \alpha$ expression vector significantly increased luciferase gene expression. Moreover, overexpression of the HNF- $1 \alpha$ expression vector also enhanced the expression of endogenous $\beta_{2}$-GPI in Huh7 cells. These observations strongly indicate that HNF- $1 \alpha$ plays an important role in the transactivation of $\beta_{2}-G P I$ promoter activity in hepatoma cells. HNF- $1 \alpha$ is also known to be important for liver-specific gene transcription [40]. There is increasing evidence that HNF-1 $\alpha$ is a crucial transcription factor involved in the regulation of plasma protein expression, including albumin and clotting factors [40,41]. The lack of $\beta_{2}-G P I$ gene expression in HeLa cells might result from their deficiency of the HNF- $1 \alpha$.

Although the mechanisms by which HNF-1 $\alpha$ co-operates with other transcription factors to regulate $\beta_{2}$-GPI gene expression is currently unknown, it has been proposed that HNF-1 $\alpha$ binding can provide a platform for the assembly of the transcription initiation machinery containing the atypical TATA box and other co-activators [42]. A similar example is the rice tungro bacilliform virus $(R T B V)$ promoter, where novel nuclear factors binding to their $c i s$-acting elements immediately downstream of the putative TATA box positively initiate transcription of the gene $R T B V$ [43]. In eukaryotic genes, many of the downstream promoter sequences are involved in basal transcription by providing sites of interaction for the TFIID complex $[44,45]$.

In conclusion, our study provides insights regarding how human $\beta_{2}$-GPI gene expression is governed by distinct liver-specific transcriptional regulation involving an atypical TATA box and the HNF- $1 \alpha$ protein. The results provide an important clue in expanding our understanding of the transcriptional mechanisms of the $\beta_{2}-G P I$ gene expression.

We thank Dr W. Tsay for providing the expression plasmid pRSV-HNF-1 $\alpha$. This work was supported by grants NSC 90-2320-B-010-060 and NSC 91-2320-B-010-076 from the National Science Council, Taiwan, R. O. C.

\section{REFERENCES}

1 Lozier, J., Takahashi, N. and Putnam, F. W. (1984) Complete amino acid sequence of human plasma $\beta_{2}$-glycoprotein I. Proc. Natl. Acad. Sci. U.S.A. 81, 3640-3364

2 Klickstein, L. B., Wong, W. W., Smith, J. A., Weis, J. H., Wilson, J. G. and Fearon, D. T. (1987) Human C3b/C4b receptor (CR1) demonstration of long homologous repeating domains that are composed of the short consensus repeats characteristic of $\mathrm{C} 3 / \mathrm{C} 4$ binding proteins. J. Exp. Med. 165, 1095-1112

3 Schwarzenbacher, R., Zeth, K., Diederichs, K., Gries, A., Kostner, G. M., Laggner, P. and Prassl, R. (1999) Crystal structure of human $\beta_{2}$-glycoprotein I: implications for phospholipid binding and the antiphospholipid syndrome. EMBO J. 18, 6228-6239

4 Polz, E. and Kostner, G. M. (1979) The binding of $\beta_{2}$-glycoprotein I to human serum lipoproteins: distribution among density fractions. FEBS Lett. 102, 183-186

5 Kamboh, M. I. and Ferrell, R. E. (1991) Apolipoprotein H polymorphism and its role in lipid metabolism. Adv. Lipid Res. 1, 9-18

6 Sheng, Y., Reddel, S. W., Herzog, H., Wang, Y. X., Brighton, T., France, M. P., Robertson, S. A. and Krilis, S. A. (2001) Impaired thrombin generation in $\beta_{2}$-glycoprotein I null mice. J. Biol. Chem. 276, 13817-13821

7 Nimpf, J., Bevers, E. M., Bomans, P. H. H., Till, U., Wurm, H., Kostner, G. M. and Zwaal, R. F. A. (1986) Prothrombinase activity of human platelets is inhibited by $\beta_{2}$-glycoprotein I. Biochim. Biophys. Acta 884, 142-149
8 Nimpf, J., Wurm, H. and Kostner, G. M. (1987) $\beta_{2}$-glycoprotein I (apoH) inhibits the release reaction of human platelets during ADP-induced aggregation. Atherosclerosis 63, 109-114

9 Lutters, B. C., Meijers, J. C., Derksen, R. H., Arnout, J. and de Groot, P. G. (2001) Dimers of $\beta_{2}$-glycoprotein I mimic the in vitro effects of $\beta_{2}$-glycoprotein I-anti- $\beta_{2}$-glycoprotein I antibody complexes. J. Biol. Chem. 276, 3060-3067

10 Roubey, R. A., Pratt, C. W., Buyon, J. P. and Winfield, J. B. (1992) Lupus anticoagulant activity of autoimmune anti-phospholipid antibodies is dependent upon $\beta_{2}$-glycoprotein I. J. Clin. Invest. 90, 1100-1104

11 Cabral, A. R., Cabiedes, J. and Alarcon-Segovia, D. (1995) Antibodies to phospholipid-free $\beta_{2}$-glycoprotein I in patients with primary anti-phospholipid syndrome. J. Rheumatol. 22, 1894-1898

12 Tsutsumi, A., Matsuura, E., Ichikawa, K., Fujisaku, A., Mukai, M., Kobayashi, S. and Koike, T. (1996) Antibodies to $\beta_{2}$-glycoprotein I and clinical manifestations in patients with systemic lupus erythematosus. Arth. Rheum. 39, 1466-1474

13 Hwang, K. K., Grossman, J. M., Visvanathan, S., Chukwuocha, R. U., Woods, Jr, V. L., Le, D. T., Hahn, B. H. and Chen, P. P. (2001) Identification of anti-thrombin antibodies in the antiphospholipid syndrome that interferes with the inactivation of thrombin by antithrombin. J. Immunol. 167, 7192-7198

14 Visvanathan, S. and McNeil, H. P. (1999) Cellular immunity to $\beta_{2}$-glycoprotein I in patients with the antiphospholipid syndrome. J. Immunol. 162, 6919-6925

15 Hasunuma, Y., Matsuura, E., Makita, Z., Katahira, T., Nishi, S. and Koike. T. (1997) Involvement of $\beta_{2}$-glycoprotein I and anticardiolipin antibodies in oxidatively modified low-density lipoprotein uptake by macrophages. Clin. Exp. Immunol. 107, $569-573$

16 Lin, K. Y., Pan, J. P., Yang, D. L., Huang, K. T., Chang, M. S., Ding, P. Y. and Chiang, A. N. (2001) Evidence for inhibition of low density lipoprotein oxidation and cholesterol accumulation by apolipoprotein $\mathrm{H}\left(\beta_{2}\right.$-glycoprotein I). Life Sci. 69, 707-719

17 Haagerup, A., Kristensen, T. and Kruse, T. (1991) Polymorphism and genetic mapping of the gene encoding human $\beta_{2}$-glycoprotein I to chromosome 17. Cytogenet. Cell Genet. 58, 2005

18 Steinkasserer, A., Cockburn, D. J., Black, D. M., Boyd, Y., Solomon, E. and Sim, R. B. (1992) Assignment of apolipoprotein $\mathrm{H}$ (APOH: $\beta_{2}$-glycoprotein I) to human chromosome 17q23-qter; determination of the major expression site. Cytogenet. Cell Genet. 60, 31-33

19 Sanghera, D. K., Kristensen, T., Hamman, R. F. and Kamboh, M. I. (1997) Molecular basis of the apolipoprotein $\mathrm{H}\left(\beta_{2}\right.$-glycoprotein I) protein polymorphism. Hum. Genet. 100, $57-62$

20 Mehdi, H., Aston, C. E., Sanghera, D. K., Hamman, R. F. and Kamboh, M. I. (1999) Genetic variation in the apolipoprotein $\mathrm{H}\left(\beta_{2}\right.$-glycoprotein I) gene affects plasma apolipoprotein $\mathrm{H}$ concentrations. Hum. Genet. 105, 63-71

21 Mehdi, H., Nunn, M., Steel, D. M., Whitehead, A. S., Perez, M., Walker, L. and Peeples, M. E. (1991) Nucleotide sequence and expression of the human gene encoding apolipoprotein $\mathrm{H}\left(\beta_{2}\right.$-glycoprotein I). Gene 108, 293-298

22 Sambrook, J., Fritsch, E. F. and Maniatis, E. F. (1989) Molecular Cloning: A Laboratory Manual, 2nd edn, Cold Spring Harbor Laboratory Press, Plainview, NY

23 You, L. R., Chen, C. M., Yeh, T. S., Tsai, T. Y., Mai, R. T., Lin, C. H. and Lee, Y. H. (1999) Hepatitis $\mathrm{C}$ virus core protein interacts with cellular putative RNA helicase. J. Virol. 73, 2841-2853

24 Okkels, H., Rasmussen, T. E., Sanghera, D. K., Kamboh, M. I. and Kristensen, T. (1999) Structure of the human $\beta_{2}$-glycoprotein I (apolipoprotein H) gene. Eur. J. Biochem. 259, $435-440$

25 Quandt, K., Frech, K., Karas, H., Wingender, E. and Werner, T. (1995) MatInd and Matlnspector: new fast and versatile tools for detection of consensus matches in nucleotide sequence data. Nucleic Acids Res. 23, 4878-4884

26 Day, J. R., O'Hara, P. J., Grant, F. J., Lofton-Day, C., Berkaw, M. N., Werner, P. and Arnaud, $P$. (1992) Molecular cloning and sequence analysis of the CDNA encoding human apolipoprotein $\mathrm{H}$ ( $\beta_{2}$-glycoprotein I). Int. J. Clin. Lab. Res. 21, 256-263

27 Kristensen, T., Schousboe, I., Boel, E., Mulvihill, E. M., Hansen, R. R., Moller, K. B., Moller, N. P. and Sottrup-Jensen, L. (1991) Molecular cloning and mammalian expression of human $\beta_{2}$-glycoprotein I cDNA. FEBS Lett. 289, 183-186

28 Steinkasserer, A., Estaller, C., Weiss, E. H., Sim, R. B. and Day, A. J. (1991) Complete nucleotide and deduced amino acid sequence of human $\beta_{2}$-glycoprotein I. Biochem. J. 277, 387-391

29 Reese, M. G. (2001) Application of a time-delay neural network to promoter annotation in the Drosophila melanogaster genome. Comput. Chem. 26, 51-56

30 Knudsen, S. (1999) Promoter 2.0: for the recognition of Polll promoter sequences. Bioinformatics 15, 356-361

31 Mendel, D. B., Hansen, L. P., Graves, M. K., Conley, P. B. and Crabtree, G. R. (1991) HNF- $1 \alpha$ and HNF-1 $\beta$ (VHNF-1) share dimerization and homeo domains, but not activation domains, and form heterodimers in vitro. Genes Dev. 5, 1042-1056 
32 Song, Y. H., Ray, K., Liebhaber, S. A. and Cooke, N. E. (1998) Vitamin D-binding protein gene transcription is regulated by the relative abundance of hepatocyte nuclear factors $1 \alpha$ and $1 \beta$. J. Biol. Chem. 273, 28408-28418

33 Mehdi, H., Manzi, S., Desai, P., Chen, Q., Nestlerode, C., Bontempo, F., Strom, S. C., Zarnegar, R. and Kamboh, M. I. (2003) A functional polymorphism at the transcriptional initiation site in $\beta_{2}$-glycoprotein I (apolipoprotein $\mathrm{H}$ ) associated with reduced gene expression and lower plasma levels of $\beta_{2}$-glycoprotein I. Eur. J. Biochem. 270, 230-238

34 Lewis, B. A., Kim, T. K. and Orkin, S. H. (2000) A downstream element in the human $\beta$-globin promoter: evidence of extended sequence-specific transcription factor IID contacts. Proc. Natl. Acad. Sci. U.S.A. 97, 7172-7177

35 Leach, K. M., Vieira, K. F., Kang, S. H., Aslanian, A., Teichmann, M., Roeder, R. G. and Bungert, J. (2003) Characterization of the human $\beta$-globin downstream promoter region. Nucleic Acids Res. 31, 1292-1301

36 Baumhueter, S., Courtois, G. and Crabtree, G. R. (1988) A variant nuclear protein in dedifferentiated hepatoma cells binds to the same functional sequences in the $\beta$-fibrinogen gene promoter as HNF-1. EMBO J. 7, 2485-2493

37 Cereghini, S., Raymondjean, M., Carranca, A. G., Herbomel, P. and Yaniv, M. (1987) Factors involved in control of tissue-specific expression of albumin gene. Cell (Cambridge, Mass.) 50, 627-638

38 Bois-Joyeux, B. and Danan, J. L. (1994) Members of the CAAT/enhancer-binding protein, hepatocyte nuclear factor-1 and nuclear factor- 1 families can differentially modulate the activities of the rat $\alpha$-fetoprotein promoter and enhancer. Biochem. J. 301, 49-55

Received 22 October 2003/19 February 2004; accepted 25 February 2004

Published as BJ Immediate Publication 25 February 2004, DOI 10.1042/BJ20031610
39 Faust, D. M., Catherin, A. M., Barbaux, S., Belkadi, L., Imaizumi-Scherrer, T. and Weiss, M. C. (1996) The activity of the highly inducible mouse phenylalanine hydroxylase gene promoter is dependent upon a tissue-specific, hormone-inducible enhancer. Mol. Cell. Biol. 16, 3125-3137

40 Tronche, F. and Yaniv, M. (1992) HNF1, a homeoprotein member of the hepatic transcription regulatory network. Bioessays 14, 579-587

41 McGlynn, L. K., Mueller, C. R., Begbie, M., Notley, C. R. and Lillicrap, D. (1996) Role of the liver-enriched transcription factor hepatocyte nuclear factor 1 in transcriptional regulation of the factor VIII gene. Mol. Cell. Biol. 16, 1936-1945

42 Soutoglou, E., Papafotiou, G., Katrakili, N. and Talianidis, I. (2000) Transcriptional activation by hepatocyte nuclear factor- 1 requires synergism between multiple coactivator proteins. J. Biol. Chem. 275, 12515-12520

$43 \mathrm{He}, \mathrm{X}$., Futterer, J. and Hohn, T. (2002) Contribution of downstream promoter elements to transcriptional regulation of the rice tungro bacilliform virus promoter. Nucleic Acids Res. 30, 497-506

44 Knutson, A., Castano, E., Oelgeschlager, T., Roeder, R. G. and Westin, G. (2000) Downstream promoter sequences facilitate the formation of a specific transcription factor IID-promoter complex topology required for efficient transcription from the megalin/low density lipoprotein receptor-related protein 2 promoter. J. Biol. Chem. 275, 14190-14197

45 Wu, C. H., Madabusi, L., Nishioka, H., Emanuel, P., Sypes, M., Arkhipova, I. and Gilmour, D. S. (2001) Analysis of core promoter sequences located downstream from the TATA element in the hsp70 promoter from Drosophila melanogaster. Mol. Cell. Biol. 21, 1593-1602 